\title{
Quantitative computed tomography features and clinical manifestations associated with the extent of bronchiectasis in patients with moderate-to- severe COPD
}

This article was published in the following Dove Press journal:

International Journal of COPD

\author{
So Hyeon Bak' \\ Soohyun $\mathrm{Kim}^{2}$ \\ Yoonki Hong ${ }^{3}$ \\ Jeongwon $\mathrm{Heo}^{4}$ \\ Myoung-Nam Lim $^{5}$ \\ Woo Jin $\mathrm{Kim}^{3}$ \\ 'Department of Radiology, School \\ of Medicine, Kangwon National \\ University, Chuncheon, Repubilc of \\ Korea; ${ }^{2}$ Department of Radiology, \\ Kangwon National University \\ Hospital, Chuncheon, Republic of \\ Korea; ${ }^{3}$ Department of Internal \\ Medicine, School of Medicine, \\ Kangwon National University, \\ Chuncheon, Republic of Korea; \\ ${ }^{4}$ Department of Internal Medicine \\ and Environmental Health Center, \\ Kangwon National University \\ Hospital, Chuncheon, Republic \\ of Korea; ${ }^{5}$ Data Analysis Center, \\ Kangwon National University, \\ Chuncheon, Republic of Korea
}

Correspondence: Woo Jin Kim Department of Internal Medicine, School of Medicine, Kangwon National University, I Kangwondaehak-gil, Chuncheon, Gangwon-do, 2434I, Republic of Korea

Tel +82 322589364

Fax +82322582404

Email wjkim47@gmail.com
Background: Few studies have investigated the quantitative computed tomography (CT) features associated with the severity of bronchiectasis in COPD patients. The purpose of this study was to identify the quantitative CT features and clinical values to determine the extent of bronchiectasis in moderate-to-severe COPD patients.

Methods: A total of 127 moderate-to-severe COPD patients were selected from the cohort of COPD in Dusty Areas (CODA). The study subjects were classified into three groups according to the extent of bronchiectasis on CT: no bronchiectasis, mild bronchiectasis, and moderate-to-severe bronchiectasis. The three groups were compared with respect to demographic data, symptoms, medical history, serum inflammatory markers, pulmonary function, and quantitative CT values.

Results: Among 127 moderate-to-severe COPD subjects, 73 patients $(57.5 \%)$ were detected to have bronchiectasis, 51 patients $(40.2 \%)$ to have mild bronchiectasis, and 22 patients $(17.3 \%)$ to have moderate-to-severe bronchiectasis. Compared with COPD patients without bronchiectasis, those with bronchiectasis were older and had higher frequency of prior tuberculosis, lower prevalence of bronchodilator reversibility (BDR), and more severe air trapping $(P<0.05)$. Moderate-to-severe bronchiectasis patients had lower body mass index (BMI), higher frequency of prior tuberculosis, lower prevalence of BDR, worse pulmonary function, and more severe air trapping $(P<0.05)$ than those in the mild bronchiectasis group.

Conclusion: Moderate-to-severe bronchiectasis was associated with a history of pulmonary tuberculosis, lower BMI, severe airflow obstruction, and lower BDR in moderate-to-severe COPD patients. Quantitative analysis of CT showed that severe air trapping was associated with the extent of bronchiectasis in these patients.

Keywords: chronic obstructive pulmonary disease, bronchiectasis, computed tomography, air trapping, tuberculosis

\section{Introduction}

COPD is a heterogeneous disease with a variable clinical course and is one of the leading causes of morbidity and mortality in the developed world. ${ }^{1,2}$ The widespread availability of computed tomography (CT) has resulted in an apparent increase in the prevalence of bronchiectasis in COPD patients. ${ }^{3}$ The Global Initiative for Chronic Obstructive Lung Disease (GOLD) defined bronchiectasis as a comorbidity of COPD. ${ }^{4}$ Bronchiectasis is characterized by the presence of permanent dilatation of one or more bronchi and mild-to-moderate airflow obstruction. ${ }^{5,6}$ Studies have reported the presence of bronchiectasis in up to $69 \%$ of COPD patients..$^{7-13}$ Inflammation is important in the 
pathogenesis of COPD and bronchiectasis. ${ }^{14,15}$ In addition, COPD and bronchiectasis share clinical presentations and pathologic mechanisms, such as productive cough and susceptibility to recurrent exacerbations. ${ }^{3,16}$

The impact of bronchiectasis on the natural history of COPD has been emphasized; moreover, early diagnosis and management of bronchiectasis are important for COPD patients. ${ }^{1,9}$ In recent meta-analyses, the presence of bronchiectasis in COPD patients was shown to be associated with higher exacerbation frequency and mortality, more severe airflow obstruction, and higher rate of isolation of potentially pathogenic microorganisms, which adequately demonstrated that bronchiectasis is more than a radiological feature. ${ }^{1,3}$ In previous studies, the analysis of CT features associated with bronchiectasis was largely qualitative. Few studies have investigated the quantitative CT features associated with the severity of bronchiectasis in COPD patients. The aim of this study was to identify the quantitative CT features and clinical values to determine the extent of bronchiectasis in moderate-to-severe COPD patients.

\section{Patients and methods Study population}

A total of 159 patients diagnosed with moderate-to-severe COPD were initially selected from the cohort of COPD in Dusty Areas (CODA), a Korean study that was designed to observe the clinical outcomes of patients living near cement factories. The design of this cohort had been previously described in detail. ${ }^{17,18}$ All enrolled patients were evaluated by medical interview, physical examination, spirometry, laboratory tests, and CT scan. COPD was defined as a postbronchodilator ratio of forced expiratory volume in 1 second $\left(\mathrm{FEV}_{1}\right) /$ forced vital capacity $(\mathrm{FVC})$ of $<0.7 .{ }^{4}$ Patients with GOLD grades 2-4 were included. The severity of airflow limitation was defined as described by the 2017 GOLD grading system as grade $2\left(50 \% \leq \mathrm{FEV}_{1}<80 \%\right)$, grade $3\left(30 \% \leq \mathrm{FEV}_{1}<50 \%\right)$, or grade $4\left(\mathrm{FEV}_{1}<30 \%\right){ }^{4}$ We excluded 32 patients with acute infection, previous pulmonary tuberculosis (TB) resulting in severe lung parenchymal distortion, pneumoconiosis with progressive massive fibrosis, a diagnosis of bronchiectasis before COPD was diagnosed, history of lobectomy, interstitial lung disease, pleural effusion, and lung cancer on chest CT. Of the 159 moderate-to-severe COPD patients who were initially considered, 127 were included in this study after exclusion. These 127 moderate-to-severe COPD patients were allocated to one of the three groups according to the extent of bronchiectasis: no bronchiectasis $(n=54)$, mild bronchiectasis $(n=51)$, and moderate-to-severe bronchiectasis $(n=22)$. The selection criteria for this study are shown in Figure 1. This study was approved by the institutional review board (IRB) of Kangwon National University Hospital (IRB number 2012-06-007), and all participants provided written informed consent.

\section{Clinical variables and pulmonary functions}

The interview questionnaire included demographic characteristics, medical history, environmental exposure, respiratory symptoms, and history of exacerbations during the previous year. The main contents of the questionnaire are presented in Table S1. Exacerbations were defined as acute events of worsening respiratory symptoms requiring treatment with systemic steroids or antibiotics, the need to visit an emergency room, or the need for hospitalization. Dyspnea was evaluated using the modified Medical Research Council (MMRC) scoring system. Health-related quality of life was evaluated using the patient-reported COPD assessment test (CAT). The study subjects were questioned regarding the history of direct exposure to biomass using the following question: "for cooking and/or heating, have you ever been exposed to fuels of wood or charcoal?" Positive biomass exposure was defined as a history of more than 10 years of direct exposure. ${ }^{19,20}$ In addition, the peripheral levels of white blood cells (WBCs), neutrophils, eosinophils, interleukin (IL)-6, IL-8, C-reactive protein (CRP), and albumin were used as markers of systemic inflammation and nutritional status.

Pulmonary function tests were performed as described by the American Thoracic Society/European Respiratory Society using the Easy One kit (NDD Medizintechnik AG, Zurich, Switzerland) to evaluate lung function and bronchodilator reversibility (BDR). ${ }^{21}$ Postbronchodilator $\mathrm{FEV}_{1}$ values were determined by spirometry before and 15 minutes after the administration of $400 \mu \mathrm{g}$ salbutamol through a metereddose inhaler with a spacer. BDR was defined as an increase of at least $12 \%$ or $200 \mathrm{~mL}^{\text {in }} \mathrm{FEV}_{1}$ or FVC after salbutamol administration. ${ }^{21,22}$

\section{Image analysis}

All patients underwent volumetric thin-section chest CT at full inspiration and expiration in a supine position. Scans were obtained using a first-generation dual-source CT system (Somatom Definition; Siemens Healthcare, Forchheim, Germany) in the caudocranial direction using the following parameters: $140 \mathrm{kVp}, 100 \mathrm{~mA}, 0.9-1$ beam pitch, and section thickness of $0.6 \mathrm{~mm}$. CT data were reconstructed using soft kernel (B30f; Siemens Medical System, Forchheim, Germany). The CT 


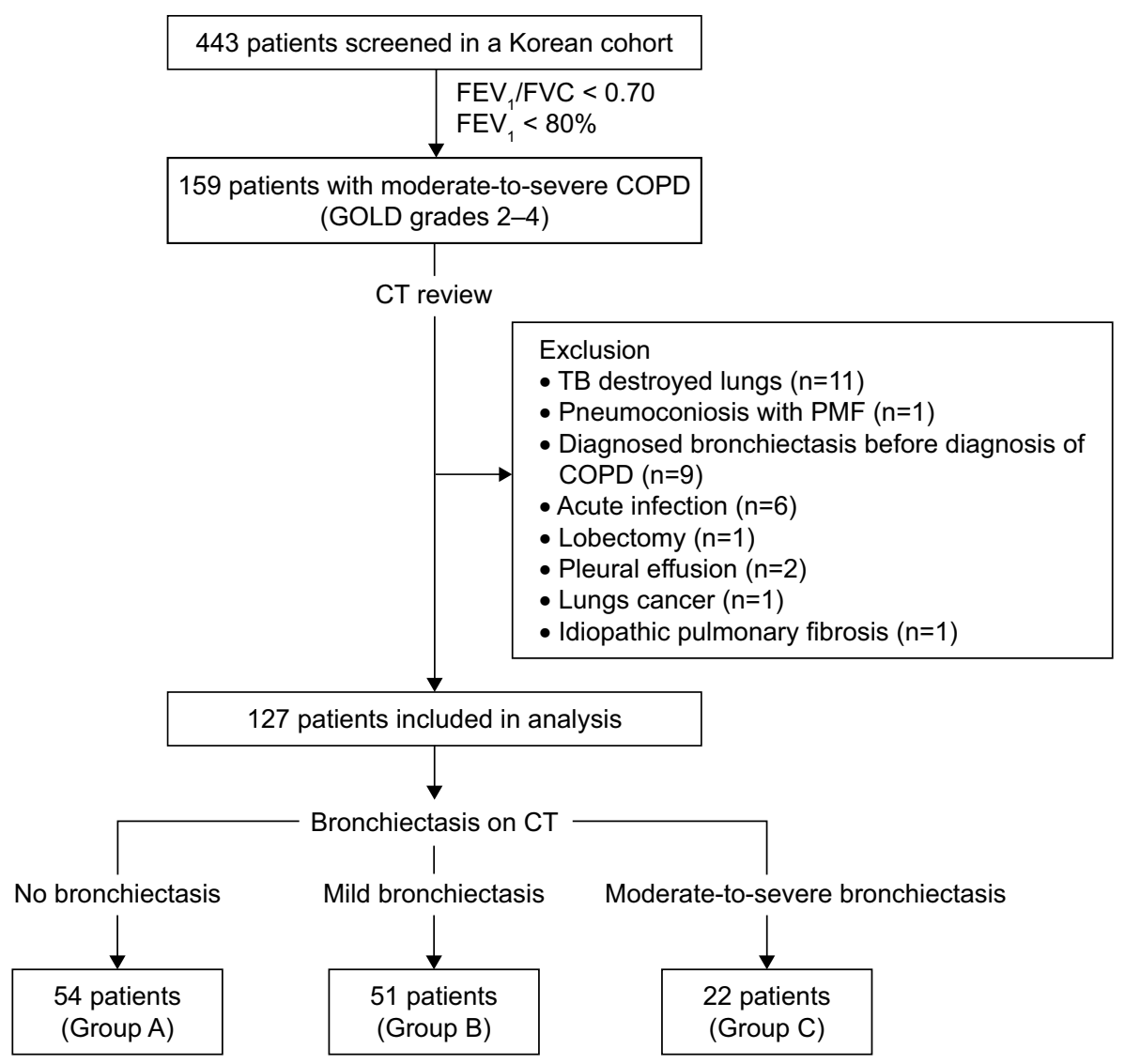

Figure I Flowchart of the study population.

Abbreviations: CT, computed tomography; FEV , forced expiratory volume in I second; FVC, forced vital capacity; GOLD, Global Initiative for Chronic Obstructive Lung Disease; PMF, progressive massive fibrosis; TB, tuberculosis.

images were obtained without injection of contrast medium. Lung window images (width, 1,500 Hounsfield unit [HU]; level, $-700 \mathrm{HU}$ ) were used to assess bronchiectasis.

Chest CT images were independently interpreted by two radiologists who were unaware of clinical data for the presence and extent of bronchiectasis. Different interpretations were resolved by consensus. The presence of bronchiectasis was determined according to Naidich et $\mathrm{al}^{23}$ as follows: 1) lack of tapering of the bronchial lumen toward the periphery; 2) dilatation of the bronchi when the internal diameter of the bronchi was greater than that of the accompanying pulmonary artery; or 3 ) the presence of peripheral bronchi within $1 \mathrm{~cm}$ of the pleura. The extent of bronchiectasis was assessed based on the number of pulmonary segments affected with the lingula considered as an independent lobe; the scores were $0=$ absence of bronchiectasis, $1=$ mild ( $1-5$ segments), $2=$ moderate $(6-9$ segments $)$, and $3=$ severe (more than 10 segments). ${ }^{24}$ Small cylindrical bronchiectatic lesions that were visible in only one pulmonary segment were ignored because these are present in a significant portion of a healthy population. ${ }^{25}$
To quantitatively assess emphysema, air trapping, and bronchial wall thickness, whole-lung images were automatically extracted from the chest wall, mediastinum, and large airway; the attenuation coefficients of pixels in these images were then measured using in-house software. Emphysema index (EI) was defined as the percentage of low attenuated area below $-950 \mathrm{HU}$ at full inspiration (Figure 2). The expiratory to inspiratory ratio of mean lung density $\left(\mathrm{E} / \mathrm{I}-\right.$ ratio $\left._{\mathrm{MLD}}\right)$ was used to evaluate air trapping. ${ }^{26,27}$ Using in-house software, the airway dimensions, including wall area (WA), lumen area, and WA\% (defined as WA/[WA + lumen area] $\times 100$ ), were measured near the origin of the right apical and left apicoposterior segmental bronchi (Figure 2). In the current study, WA\% was used to assess airway thicknesses; the mean values of the segmental bronchi were used in the statistical analyses.

\section{Determination of previous TB infection or pneumoconiosis}

History of pulmonary TB was defined as the presence of pleural thickening, traction bronchiectasis, parenchymal 

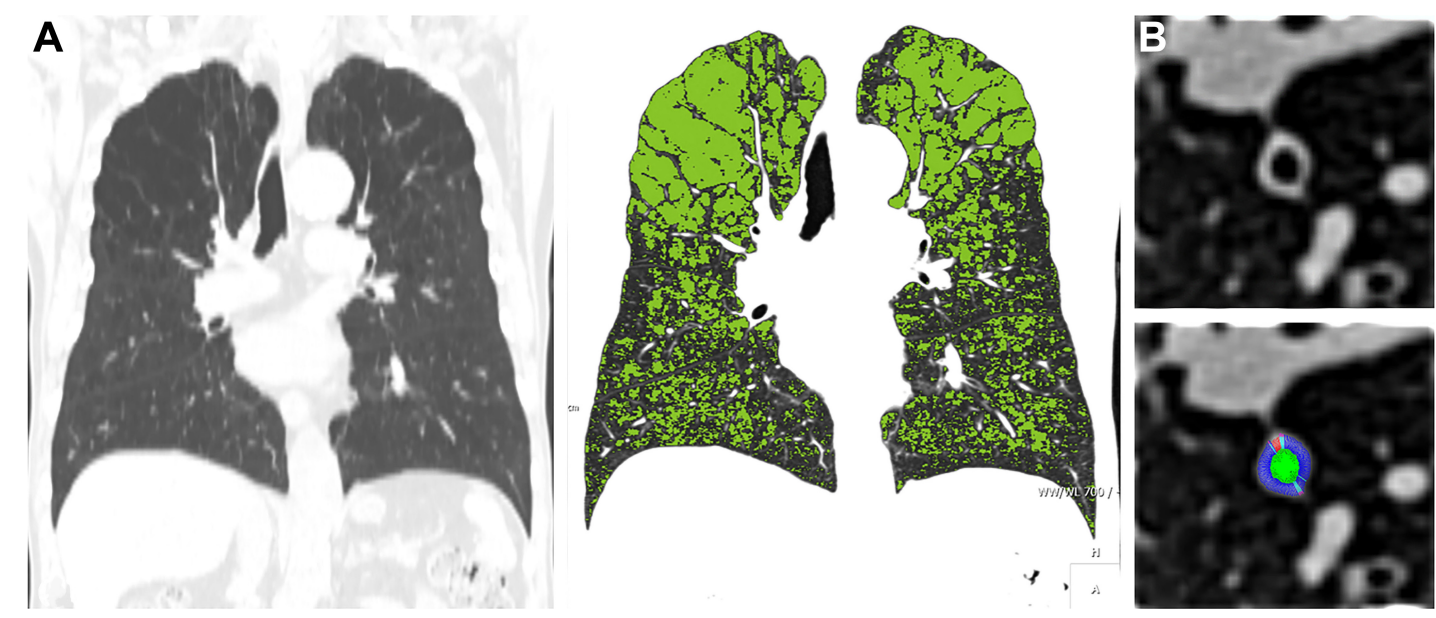

Figure 2 Quantitative CT analysis of emphysema and bronchial wall thickness.

Notes: (A) CT attenuation masks show areas of less than $-950 \mathrm{HU}$ (green areas). (B) Cross-sectional image shows segmentation of the airway wall at the origin of left apicoposterior segmental bronchi.

Abbreviations: $\mathrm{CT}$, computed tomography; $\mathrm{HU}$, Hounsfield unit.

bands, cicatrization atelectasis, or sharply defined nodules with the upper lung predominance on $\mathrm{CT}$ images and/or a previous diagnosis of pulmonary TB. ${ }^{28}$ All patients had parenchymal or pleural changes due to previous TB on CT. Pneumoconiosis was defined by the following criteria: 1) history of diagnosed pneumoconiosis or 2) history of direct exposure to biomass plus visualization of perilymphatic nodules, reticular opacities, progressive massive fibrosis with upper lobe predominance, or lymph node enlargement with egg shell calcification. ${ }^{29}$

\section{Statistical analyses}

Parametric data were expressed as mean $\pm \mathrm{SD}$, whereas nonparametric data were expressed as numbers and percentages. The Student's $t$-test or the Chi-square test was used to determine the significance of differences between patients with bronchiectasis and those without bronchiectasis. Analysis of variance or the Chi-square test was used to determine the significance of differences among the three groups of the extent of bronchiectasis. Multivariate logistic regression analysis, which was adjusted for sex, smoking, and body mass index (BMI), was used to identify the factors independently associated with bronchiectasis. Statistical significance was accepted for $P$-values $<0.05$. Data analysis was performed using SAS version 9.3 (SAS Institute Inc., Cary, NC, USA).

\section{Results}

\section{Patient characteristics}

The characteristics of the patients are summarized in Table S2. All 127 study subjects had moderate-to-severe COPD and had a mean age of $71.5 \pm 7.6$ years (range, 48-96 years); $107(84.3 \%)$ were men. GOLD severity was grade 2 in 107 (84.2\%), grade 3 in $18(14.2 \%)$, and grade 4 in 2 (1.6\%). A total of $40(31.5 \%)$ patients had a history of pulmonary TB, and eight (6.3\%) patients had a history of pneumoconiosis.

\section{COPD with and without bronchiectasis}

Of the 127 study subjects, 73 (57.5\%) presented with bronchiectasis, which was most frequently detected in the lower lobes (47.2\%; Figure 3); the mean score for the extent of bronchiectasis in these patients was 1.34 . Bronchiectasis was not associated with sex, smoking status, GOLD grade, exacerbation, BMI, MMRC dyspnea scale, CAT score, history of pneumoconiosis, inflammatory markers, bronchial wall thickness, or emphysema severity $(P>0.05)$. COPD patients with comorbid bronchiectasis were older $(72.9 \pm 7.0$ vs $69.8 \pm 8.1, P=0.024)$, had higher prevalence of previous pulmonary TB $(43.8 \%$ vs $14.8 \%, P=0.001)$, had lower prevalence of positive BDR ( $16.4 \%$ vs $35.2 \%, P=0.015)$,

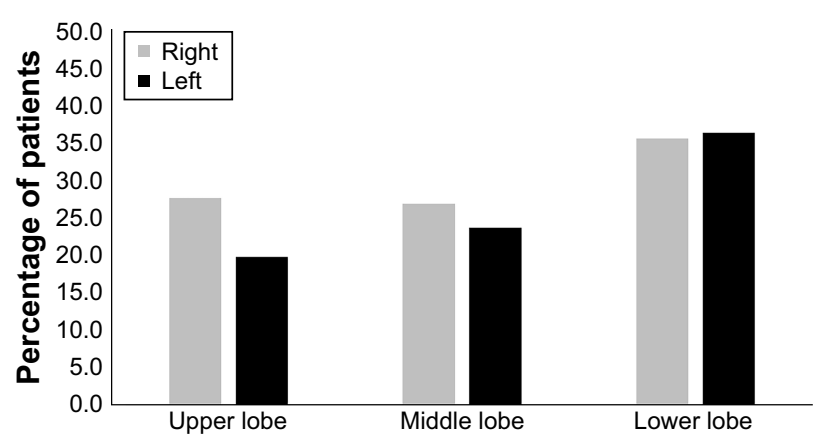

Figure 3 Distribution of bronchiectasis.

Note: The left lingua was considered an independent lobe. 
Table I Factors associated with bronchiectasis in a logistic regression model (adjusted for sex, smoking, and BMI)

\begin{tabular}{lllll}
\hline Factors & B & $\operatorname{Exp}(\mathbf{B})$ & $\mathbf{9 5 \%} \mathbf{C l}$ & $\boldsymbol{P}$-value \\
\hline Male & -0.0108 & 0.979 & $0.171-5.597$ & $0.98 I$ \\
Current smoker & 0.0472 & 0.962 & $0.185-4.998$ & 0.896 \\
Former smoker & -0.1331 & 0.803 & $0.163-3.964$ & 0.697 \\
BMI & -0.0319 & 0.969 & $0.850-1.104$ & 0.632 \\
Previous TB & 0.7316 & 4.320 & $1.735-10.753$ & $\mathbf{0 . 0 0 2}$ \\
Age & 0.0282 & 1.029 & $0.970-1.091$ & 0.348 \\
BDR, FEV & -0.3816 & 0.466 & $0.181-1.199$ & 0.113 \\
\hline
\end{tabular}

Note: Data in bold are statistically significant.

Abbreviations: B, B coefficient; BDR, bronchodilator reversibility; BMI, body mass index; $F V_{1}$, forced expiratory volume in I second; TB, tuberculosis.

and exhibited more severe air trapping than patients without bronchiectasis $(1.0 \pm 0.0$ vs $0.9 \pm 0.0 . P=0.016$; Table 1$)$. Multivariate logistic regression analysis showed that a history of pulmonary TB independently predicted the presence of bronchiectasis in COPD patients $(P=0.002)$.

\section{Factors associated with the extent of bronchiectasis}

A summary of the comparisons among the three groups according to the extent of bronchiectasis is provided in Table 2. No significant intergroup differences were observed for age, sex, smoking status, MMRC dyspnea scale, CAT score, exacerbations, history of pneumoconiosis, bronchial wall thickness, and emphysema extent $(P>0.05)$. As the extent of bronchiectasis increased, the BMIs decreased $(P=0.015)$ and the number of patients with previous TB increased $(P=0.002)$. Moreover, COPD patients with moderate-to-severe bronchiectasis had more severe airflow obstruction $\left(\mathrm{FEV}_{1} \%, P=0.010\right)$, lower prevalence of positive $\operatorname{BDR}(P=0.049)$, and more severe air trapping $(P=0.042)$. Inflammatory markers, including IL-6 and CRP, tended to increase in moderate-to-severe bronchiectasis patients, but this was not significant. Multivariate logistic regression analysis showed that a history of pulmonary TB independently predicted the mild bronchiectasis in COPD patients $(P=0.002$; Table 3).

\section{Discussion}

The current study evaluated the quantitative CT features and clinical manifestations associated with the extent of bronchiectasis in moderate-to-severe COPD patients. We found that the history of TB, lower BMI, more severe airflow obstruction, lower prevalence of positive BDR, and more severe air trapping were associated with the extent of bronchiectasis in moderate-to-severe COPD patients.
Furthermore, a history of pulmonary TB was found to independently predict the presence of bronchiectasis.

Previous studies have reported a prevalence of bronchiectasis ranging from $50.0 \%$ to $57.6 \%$ in moderateto-severe COPD patients. ${ }^{8,10,11,30}$ In the current study, the prevalence of bronchiectasis in these patients was $57.5 \%$. The prevalence of bronchiectasis in Korea health screening examinations was $9.1 \% .{ }^{31}$ Based on our results, the proportion of bronchiectasis in moderate-to-severe COPD patients was significantly higher compared with the healthy subjects in Korea. Most of the patients in our study were male $(84.3 \%)$. The prevalence of COPD in 2015 using the data from Korea National Health and Nutrition Examination Survey (KNHANES) was $21.6 \%$ in male and 5.8\% in female. ${ }^{32}$ Considering the sex ratio of COPD patients in Korea, the proportion of subjects in our study seems to be similar. Similar to previous studies, ${ }^{11,30}$ the current study showed that bronchiectasis was most frequently detected in the lower lobes (47.2\%). Patel et $\mathrm{al}^{30}$ reported bronchiectasis in the upper lobes in $11.3 \%$ of patients; however, in the current study, the predilection for upper lobe bronchiectasis was substantially higher at $34.6 \% .{ }^{33}$ Bronchiectasis has been reported to show upper lobe predominance in patients with a history of pulmonary $\mathrm{TB} ;{ }^{14}$ notably, the relatively high rate $(31.5 \%)$ of history of pulmonary TB in our study population may explain the higher predilection for upper lobe bronchiectasis. Jin et $\mathrm{al}^{8}$ found that previous TB was an independent risk factor for coexistent bronchiectasis in COPD patients in China. Because of the high prevalence of TB, post-TB bronchiectasis in Asian was more common than that in Europe. ${ }^{33}$ Previous TB infection was an important risk factor for the development of bronchiectasis in subjects who underwent a health screening examinations in Korea. ${ }^{31}$ Severely destructed lungs with TB may lead to severe bronchiectasis, and airflow limitation can occur due to post-TB bronchiectasis rather than COPD. To minimize the effect of airflow limitation mainly caused by bronchiectasis, we excluded 20 patients who had severely destructed lungs with $\mathrm{TB}$ and were diagnosed as having bronchiectasis before the diagnosis of COPD. In the current study, multivariate logistic analysis showed that previous TB was independently associated with the presence of bronchiectasis in COPD patients even after the exclusion of patients with prior pulmonary TB with destroyed lungs $(P=0.002)$. These results suggested that COPD patients with a history of pulmonary TB were more likely to have more extensive and severe bronchiectasis and other clinical manifestations compared with COPD patients without prior pulmonary TB. 
Table 2 Characteristics of 127 patients in association with the extent of bronchiectasis

\begin{tabular}{|c|c|c|c|c|}
\hline Parameter & $\begin{array}{l}\text { No } \\
\text { bronchiectasis }\end{array}$ & $\begin{array}{l}\text { Mild } \\
\text { bronchiectasis }\end{array}$ & $\begin{array}{l}\text { Moderate-to-severe } \\
\text { bronchiectasis }\end{array}$ & $P$-value \\
\hline Subjects, n (\%) & $54(42.5)$ & $51(40.2)$ & $22(17.3)$ & \\
\hline Age* & $69.8 \pm 8.1$ & $72.5 \pm 6.9$ & $73.7 \pm 7.3$ & 0.064 \\
\hline Male & $47(87.0)$ & $43(84.3)$ & $17(77.3)$ & 0.570 \\
\hline Smoking status & & & & 0.866 \\
\hline Current & $18(34.0)$ & $19(38.0)$ & $6(28.6)$ & \\
\hline Former & $25(47.2)$ & $21(42.0)$ & $9(42.9)$ & \\
\hline Never & $10(18.9)$ & $10(20.0)$ & $6(28.6)$ & \\
\hline Pack-years smoked* & $27.6 \pm 24.4$ & $29.6 \pm 23.4$ & $40.3 \pm 31.4$ & 0.243 \\
\hline GOLD grade & & & & 0.013 \\
\hline Grade 2 & $45(83.3)$ & $48(94.1)$ & $14(63.6)$ & \\
\hline Grade 3 & $9(16.7)$ & $2(3.9)$ & $7(31.8)$ & \\
\hline Grade 4 & $0(0.0)$ & I (2.0) & I (4.6) & \\
\hline BMI,* kg/m² & $23.2 \pm 3.1$ & $23.0 \pm 3.5$ & $20.8 \pm 3.2$ & 0.015 \\
\hline Previous TB & $8(14.8)$ & $2 \mid(4 I .2)$ & II (50.0) & 0.002 \\
\hline Pneumoconiosis & $5(9.3)$ & $2(3.9)$ & I (4.6) & 0.497 \\
\hline MMRC $\S$ & $10 / 23 / 6 / 9 / 5$ & $10 / 21 / 6 / 11 / 2$ & $3 / 7 / 4 / 5 / 2$ & 0.927 \\
\hline CAT score* & $18.7 \pm 10.7$ & $17.9 \pm 8.7$ & $21.3 \pm 10.3$ & 0.425 \\
\hline \multicolumn{5}{|l|}{ Respiratory symptom } \\
\hline Cough & $34(63.0)$ & $36(70.6)$ & $19(86.4)$ & 0.129 \\
\hline Sputum & $39(72.2)$ & $39(76.5)$ & I8 (8I.8) & 0.665 \\
\hline Dyspnea & $27(50.0)$ & $31(60.8)$ & I3 (59.I) & 0.510 \\
\hline History of pneumonia & $6(11.5)$ & $3(6.1)$ & $3(14.3)$ & 0.763 \\
\hline History of asthma & $14(26.9)$ & $8(16.3)$ & $5(23.8)$ & 0.296 \\
\hline \multicolumn{5}{|l|}{ Exacerbations } \\
\hline Steroid treatment & I (I.9) & I (2.0) & I (4.6) & 0.740 \\
\hline Hospital admissions & $2(3.7)$ & I (2.0) & $2(9.5)$ & 0.333 \\
\hline $\mathrm{WBC}, * \times 10^{3} \mu \mathrm{L}$ & $7.0 \pm 2.0$ & $6.8 \pm 1.9$ & $6.4 \pm 1.6$ & 0.418 \\
\hline Segmenter neutrophils, ${ }^{*} \mu \mathrm{L}$ & $4,120.0 \pm 1,630.1$ & $4,069.4 \pm 1,489.1$ & $3,910.7 \pm 1,146.9$ & 0.859 \\
\hline Eosinophils, ${ }^{*} \mu \mathrm{L}$ & $169.4 \pm 130.5$ & $188.1 \pm 146.7$ & $223.8 \pm 426.2$ & 0.609 \\
\hline Albumin,* g/dL & $4.1 \pm 0.4$ & $4.1 \pm 0.5$ & $4.0 \pm 0.3$ & 0.210 \\
\hline IL-6,* pg/mL & $2.1 \pm 2.6$ & $2.5 \pm 3.0$ & $4.1 \pm 4.2$ & 0.059 \\
\hline IL-8,* pg/mL & $15.3 \pm 13.0$ & $18.1 \pm 23.1$ & $15.7 \pm 8.1$ & 0.728 \\
\hline $\mathrm{CRP}, * \mathrm{mg} / \mathrm{dL}$ & $0.2 \pm 0.3$ & $0.3 \pm 0.4$ & $0.5 \pm 0.8$ & 0.066 \\
\hline BDR, FEV & $19(35.2)$ & $9(17.7)$ & $3(13.6)$ & 0.049 \\
\hline BDR, FVC & $18(33.3)$ & $18(35.3)$ & $4(18.2)$ & 0.327 \\
\hline FVC,*\% & $85.3 \pm 15.2$ & $87.7 \pm 14.5$ & $85.5 \pm 20.2$ & 0.699 \\
\hline $\mathrm{FEV}_{1}, * \%$ & $64.7 \pm 11.8$ & $66.3 \pm 10.7$ & $57.1 \pm 14.6$ & 0.010 \\
\hline $\mathrm{FEV}_{1} / \mathrm{FVC}$,* ratio & $56.0 \pm 7.6$ & $55.3 \pm 8.2$ & $49.2 \pm 11.7$ & 0.007 \\
\hline Mean WA* & $70.8 \pm 4.6$ & $69.8 \pm 6.0$ & $69.5 \pm 5.4$ & 0.500 \\
\hline E/I-ratio ${ }_{M L D} *$ & $0.9 \pm 0.0$ & $1.0 \pm 0.0$ & $\mathrm{I} .0 \pm 0.0$ & 0.042 \\
\hline El* & $9.5 \pm 7.8$ & $8.8 \pm 8.0$ & $12.4 \pm 11.0$ & 0.260 \\
\hline
\end{tabular}

Notes: Data shown are frequencies; those in parentheses are percentages. *Data shown are the mean \pm SD values, unless indicated otherwise. ${ }^{\circledR}$ Data shown as number of scores for each $\mathrm{mMRC}$ grade from $0-4$, respectively. Data in bold are statistically significant.

Abbreviations: BDR, bronchodilator reversibility; BMI, body mass index; CAT, COPD assessment test; CRP, C-reactive protein; El, emphysema index; E/I-ratio ${ }_{\text {MLD }}$ expiratory to inspiratory ratio of mean lung density; $\mathrm{FEV}_{1}$, forced expiratory volume in I second; FVC, forced vital capacity; GOLD, Global Initiative for Chronic Obstructive Lung Disease; IL, interleukin; MMRC, Modified Medical Research Council; TB, tuberculosis; WA, wall area; WBC, white blood cell.

Morphologic changes, such as emphysema, air trapping, and bronchial wall thickening are $\mathrm{CT}$ characteristics of COPD; in fact, quantitative analysis of these morphologic changes has been performed in COPD patients. ${ }^{34}$ On the other hand, only few studies have performed quantitative $\mathrm{CT}$ analysis of the morphologic changes in COPD patients with bronchiectasis. In this study, we quantitatively assessed emphysema, air trapping, and bronchial wall thickening, as well as the association between the extent of bronchiectasis and quantitative CT features, in moderate-to-severe COPD patients and found that air trapping was associated with the extent of bronchiectasis in COPD patients. Air trapping, which reflects small airway disease, is common in patients with bronchiectasis even when it is mild. ${ }^{35,36}$ The pathologic 
Table 3 Factors associated with mild bronchiectasis in a logistic regression model (adjusted for sex, smoking, and BMI)

\begin{tabular}{lllll}
\hline Factors & B & Exp (B) & 95\% Cl & P-value* \\
\hline Male & -0.0302 & $0.94 I$ & $0.155-5.735$ & 0.948 \\
Current smoker & 0.1686 & 1.190 & $0.215-6.601$ & 0.664 \\
Former smoker & -0.1632 & 0.854 & $0.164-4.449$ & 0.653 \\
BMI & 0.0470 & 1.048 & $0.902-1.218$ & 0.540 \\
Previous TB & 0.6359 & 3.567 & $1.360-9.352$ & $\mathbf{0 . 0 1 0}$ \\
Age & 0.0423 & 1.043 & $0.979-1.11 \mathrm{I}$ & 0.191 \\
BDR, FEV & -0.4965 & 0.370 & $0.132-1.040$ & 0.059
\end{tabular}

Note: *Data in bold are statistically significant.

Abbreviations: B, B coefficient; BDR, bronchodilator reversibility; BMI, body mass index; $\mathrm{FEV}_{1}$, forced expiratory volume in I second; TB, tuberculosis.

status of small airway disease was confirmed in lobectomy specimens of patients with bronchiectasis. ${ }^{36-38}$ Air trapping was detected in $17 \%$ of the lobes without bronchiectasis on CT images, which suggested that small airway inflammation may precede the development of overt bronchiectasis. ${ }^{35,36}$ A previous study reported that the severity of bronchiectasis was correlated with the severity of bronchial wall thickening. ${ }^{?}$ However, we found no relation between bronchial wall thickening and the extent of bronchiectasis in this study. Bronchiectasis is usually encountered in the lower lobes due to the gravity-dependent retention of infectious secretions. ${ }^{6}$ In COPD patients, the extent of bronchiectasis in the upper airways tends to be less than that observed in other bronchiectasis patients. ${ }^{6}$ In the current study, the airway dimensions were measured near the origins of the right apical and left apicoposterior segmental bronchi. Therefore, our measurements may have not reflected the overall bronchial wall thickness.

A recent study suggested that greater reversibility of airflow limitation at baseline was associated with better long-term outcomes in COPD patients without significant comorbidities. ${ }^{39}$ Chronic inflammation in bronchiectasis leads to bronchomalacia or excessive collapsibility, resulting in obstructive airway physiology. ${ }^{40,41}$ However, few studies have investigated the association between bronchiectasis and BDR in moderate-to-severe COPD patients. In one study, BDR and the radiological manifestations of bronchiectasis were unrelated, ${ }^{42}$ whereas in the current study, moderateto-severe bronchiectasis patients showed lower prevalence of positive BDR. As the extent of bronchiectasis increased, more irreversible bronchial changes were considered to result in lower BDR in moderate-to-severe COPD patients. The significance of BDR, its association with the clinical parameters, and the prognostic implications require further investigation in COPD patients with bronchiectasis.
Previous analyses revealed that COPD patients with bronchiectasis presented with more symptoms and more severe exacerbations. ${ }^{1,3}$ However, we found no relationship between the presence of bronchiectasis and symptoms or exacerbations. In this study, $84.2 \%$ of the patients were in GOLD grade 2 and exacerbations occurred in few subjects compared with the findings in other studies. In the current study, we first attempted to identify the association between bronchiectasis and CAT scores. However, no relationship between the two was found in moderate-to-severe COPD patients, presumably because of few patients with GOLD grades 3 and 4 . However, moderate-to-severe bronchiectasis patients had a higher CAT score than those without bronchiectasis, although this was not statistically significant.

This study had several limitations. First, $70 \%$ of moderate-to-severe COPD patients with bronchiectasis showed mild bronchiectasis in our study. The results of our study did not fully reflect what may be seen in moderateto-severe bronchiectasis. Second, the fact that we did not control for patient's treatment as a variable could have caused bias. Third, we did not evaluate the severity of bronchiectasis using the Bhalla et $\mathrm{al}^{24}$ score system, which is used to quantify the severity of bronchiectasis on CT. Subsequent studies are needed to evaluate the association between the severity of bronchiectasis using the Bhalla score and quantitative CT features. Finally, in this study, the potentially pathogenic microorganisms that are known to be associated with bronchiectasis and their effects were not evaluated.

\section{Conclusion}

We found that moderate-to-severe bronchiectasis was associated with lower BMI, more frequent history of TB, severe airflow obstruction, and lower BDR in moderate-to-severe COPD patients. In addition, quantitative analysis of CT showed that severe air trapping was associated with the extent of bronchiectasis in moderate-to-severe COPD patients.

\section{Acknowledgments}

The authors would like to thank the CT technologists at the Department of Radiology, Kangwon National University Hospital. This work was supported by a grant from the Ministry of Environment (Environmental Health Center), Republic of Korea.

\section{Author contributions}

All of the authors contributed to the conception and design of the study, acquisition or analysis of data, interpretation of 
data, and drafting the manuscript, gave final approval of the version to be published, and agree to be accountable for all aspects of the work.

\section{Disclosure}

The authors report no conflicts of interest in this work.

\section{References}

1. Du Q, Jin J, Liu X, Sun Y. Bronchiectasis as a comorbidity of chronic obstructive pulmonary disease: a systematic review and meta-analysis. PLoS One. 2016;11(3):e0150532.

2. Kim WJ, Lee CY. Environmental exposures and chronic obstructive pulmonary disease. Mol Cell Toxicol. 2017;13:251-255.

3. Ni Y, Shi G, Yu Y, Hao J, Chen T, Song H. Clinical characteristics of patients with chronic obstructive pulmonary disease with comorbid bronchiectasis: a systemic review and meta-analysis. Int $J$ Chron Obstruct Pulmon Dis. 2015;10:1465-1475.

4. Vogelmeier CF, Criner GJ, Martinez FJ, et al. Global strategy for the diagnosis, management, and prevention of chronic obstructive lung disease 2017 report. GOLD executive summary. Am J Respir Crit Care Med. 2017;195(5):557-582.

5. Amalakuhan B, Maselli DJ, Martinez-Garcia MA. Update in bronchiectasis 2014. Am J Respir Crit Care Med. 2015;192(10):1155-1161.

6. King PT. The pathophysiology of bronchiectasis. Int J Chron Obstruct Pulmon Dis. 2009;4:411-419.

7. Gatheral T, Kumar N, Sansom B, et al. COPD-related bronchiectasis; independent impact on disease course and outcomes. COPD. 2014; 11(6):605-614.

8. Jin J, Yu W, Li S, Lu L, Liu X, Sun Y. Factors associated with bronchiectasis in patients with moderate-severe chronic obstructive pulmonary disease. Medicine. 2016;95(29):e4219.

9. Mao B, Lu HW, Li MH, et al. The existence of bronchiectasis predicts worse prognosis in patients with COPD. Sci Rep. 2015;5:10961.

10. Martinez-Garcia MA, de la Rosa Carrillo D, Soler-Cataluna JJ, et al. Prognostic value of bronchiectasis in patients with moderate-to-severe chronic obstructive pulmonary disease. Am J Respir Crit Care Med.2013; 187(8):823-831.

11. Martinez-Garcia MA, Soler-Cataluna JJ, Donat Sanz Y, et al. Factors associated with bronchiectasis in patients with COPD. Chest. 2011; 140(5):1130-1137.

12. O'Brien C, Guest PJ, Hill SL, Stockley RA. Physiological and radiological characterisation of patients diagnosed with chronic obstructive pulmonary disease in primary care. Thorax. 2000;55(8):635-642.

13. Roche N, Kouassi B, Rabbat A, Mounedji A, Lorut C, Huchon G. Yield of sputum microbiological examination in patients hospitalized for exacerbations of chronic obstructive pulmonary disease with purulent sputum. Respiration. 2007;74(1):19-25.

14. Milliron B, Henry TS, Veeraraghavan S, Little BP. Bronchiectasis: mechanisms and imaging clues of associated common and uncommon diseases. Radiographics. 2015;35(4):1011-1030.

15. Nurwidya F, Damayanti T, Yunus F. The role of innate and adaptive immune cells in the immunopathogenesis of chronic obstructive pulmonary disease. Tuber Respir Dis. 2016;79(1):5-13.

16. Hurst JR, Elborn JS, De Soyza A. COPD-bronchiectasis overlap syndrome. Eur Respir J. 2015;45(2):310-313.

17. Hahm CR, Lim MN, Kim HY, et al. Implications of the pulmonary artery to ascending aortic ratio in patients with relatively mild chronic obstructive pulmonary disease. J Thorac Dis. 2016;8(7):1524-1531.

18. Koo HK, Hong Y, Lim MN, Yim JJ, Kim WJ. Relationship between plasma matrix metalloproteinase levels, pulmonary function, bronchodilator response, and emphysema severity. Int J Chron Obstruct Pulmon Dis. 2016;11:1129-1137.
19. Hong Y, Ji W, An S, Han SS, Lee SJ, Kim WJ. Sex differences of COPD phenotypes in nonsmoking patients. Int J Chron Obstruct Pulmon Dis. 2016;11:1657-1662.

20. Ji W, Lim MN, Bak SH, et al. Differences in chronic obstructive pulmonary disease phenotypes between non-smokers and smokers. Clin Respir J. 2018;12(2):666-673.

21. Miller MR, Hankinson J, Brusasco V, et al. Standardisation of spirometry. Eur Respir J. 2005;26(2):319-338.

22. Pellegrino R, Viegi G, Brusasco V, et al. Interpretative strategies for lung function tests. Eur Respir J. 2005;26(5):948-968.

23. Naidich DP, McCauley DI, Khouri NF, Stitik FP, Siegelman SS. Computed tomography of bronchiectasis. J Comput Assist Tomogr. 1982; 6(3):437-444.

24. Bhalla M, Turcios N, Aponte V, et al. Cystic fibrosis: scoring system with thin-section CT. Radiology. 1991;179(3):783-788.

25. Lynch DA, Newell JD, Tschomper BA, Cink TM, Newman LS, Bethel R. Uncomplicated asthma in adults: comparison of CT appearance of the lungs in asthmatic and healthy subjects. Radiology. 1993; 188(3):829-833.

26. Lee YK, Oh YM, Lee JH, et al. Quantitative assessment of emphysema, air trapping, and airway thickening on computed tomography. Lung. 2008;186(3):157-165.

27. Mets OM, Zanen P, Lammers JW, et al. Early identification of small airways disease on lung cancer screening CT: comparison of current air trapping measures. Lung. 2012;190(6):629-633.

28. Kim HY, Song KS, Goo JM, Lee JS, Lee KS, Lim TH. Thoracic sequelae and complications of tuberculosis. Radiographics. 2001;21(4):839-858. discussion 859-860.

29. Chong S, Lee KS, Chung MJ, Han J, Kwon OJ, Kim TS. Pneumoconiosis: comparison of imaging and pathologic findings. Radiographics. 2006;26(1):59-77.

30. Patel IS, Vlahos I, Wilkinson TM, et al. Bronchiectasis, exacerbation indices, and inflammation in chronic obstructive pulmonary disease. Am J Respir Crit Care Med. 2004;170(4):400-407.

31. Kwak HJ, Moon JY, Choi YW, et al. High prevalence of bronchiectasis in adults: analysis of CT findings in a health screening program. Tohoku J Exp Med. 2010;222(4):237-242.

32. Hwang YI, Park YB, Yoo KH. Recent trends in the prevalence of chronic obstructive pulmonary disease in Korea. Tuberc Respir Dis. 2017; 80(3):226-229.

33. Gao YH, Guan WJ, Liu SX, et al. Aetiology of bronchiectasis in adults: a systematic literature review. Respirology. 2016;21(8):1376-1383.

34. Matsuoka S, Yamashiro T, Washko GR, Kurihara Y, Nakajima Y, Hatabu H. Quantitative CT assessment of chronic obstructive pulmonary disease. Radiographics. 2010;30(1):55-66.

35. Bonavita J, Naidich DP. Imaging of bronchiectasis. Clin Chest Med. 2012;33(2):233-248.

36. Hansell DM, Wells AU, Rubens MB, Cole PJ. Bronchiectasis: functional significance of areas of decreased attenuation at expiratory CT. Radiology. 1994;193(2):369-374.

37. Churchill ED. The segmental and lobular physiology and pathology of the lung. J Thorac Surg. 1949;18(3):279-293.

38. Culiner MM. Obliterative bronchitis and bronchiolitis with bronchiectasis. Dis Chest. 1963;44:351-360.

39. Marin JM, Ciudad M, Moya V, et al. Airflow reversibility and long-term outcomes in patients with COPD without comorbidities. Respir Med. 2014;108(8):1180-1188.

40. Nishino M, Siewert B, Roberts DH, et al. Excessive collapsibility of bronchi in bronchiectasis: evaluation on volumetric expiratory highresolution CT. J Comput Assist Tomogr. 2006;30(3):474-478.

41. Nishino M, Washko GR, Hatabu H. Volumetric expiratory HRCT of the lung: clinical applications. Radiol Clin North Am. 2010;48(1): 177-183.

42. Guan WJ, Gao YH, Xu G, et al. Bronchodilator response in adults with bronchiectasis: correlation with clinical parameters and prognostic implications. J Thorac Dis. 2016;8(1):14-23. 


\section{Supplementary materials}

Table SI The interview questionnaire

\begin{tabular}{|c|c|}
\hline Category & Items \\
\hline \multirow[t]{4}{*}{ Respiratory symptoms } & Mark all symptoms that have been in the past 12 months \\
\hline & When did the current respiratory symptoms first occur? \\
\hline & Do you still have symptoms? \\
\hline & Select all when respiratory symptoms get worse \\
\hline \multirow[t]{5}{*}{ Cough } & Since when did you have a cough? \\
\hline & Do you have a cough for 3 months or more during the year? \\
\hline & Do you have sputum when you cough? \\
\hline & How often have you had a cough in the past year? \\
\hline & Mark how often you cough by dividing into daytime and nighttime \\
\hline \multirow[t]{4}{*}{ Sputum } & Since when did you have sputum? \\
\hline & Do you have sputum for consecutive 3 months or more during the year? \\
\hline & Do you have more than 2 years of sputum persisting for more than 3 months a year? \\
\hline & Do you have a lot of sputum during the day? \\
\hline \multirow[t]{3}{*}{ Wheezing } & Since when did wheezing occur? \\
\hline & How often have you been wheezing in the past year? \\
\hline & Do you have symptoms of chest tightness or dyspnea when you wheeze? \\
\hline \multirow[t]{2}{*}{ Dyspnea } & Since when did dyspnea occur? \\
\hline & How often have you had difficulty in breathing during the past year? \\
\hline \multirow[t]{2}{*}{$\begin{array}{l}\text { Severity and frequency of } \\
\text { exacerbation }\end{array}$} & $\begin{array}{l}\text { Have you been treated with antibiotics or steroids during the past year due to exacerbation of worsened respiratory } \\
\text { symptoms (cough, dyspnea, wheezing, etc)? (except hospitalization) }\end{array}$ \\
\hline & $\begin{array}{l}\text { Have you "been hospitalized" for the past year due to exacerbation of respiratory symptoms (cough, dyspnea, } \\
\text { wheezing, etc)? }\end{array}$ \\
\hline \multicolumn{2}{|r|}{ ( } \\
\hline \multirow[t]{2}{*}{ Smoking } & What is your smoking status? \\
\hline & Have you experienced secondhand smoking because of family or coworkers? \\
\hline \multirow[t]{4}{*}{ Rhinitis symptoms } & Do you have at least one of the following: nasal obstruction, runny nose, sneezing, or itchy nose/eyes? \\
\hline & Since when did you have rhinitis symptoms (nasal obstruction, runny nose, sneezing, or itchy nose/eyes? \\
\hline & How frequently do rhinitis symptoms occur? \\
\hline & Are you uncomfortable with rhinitis symptoms in daily life? \\
\hline \multicolumn{2}{|l|}{$\begin{array}{l}\text { Past medical history of } \\
\text { respiratory disease }\end{array}$} \\
\hline $\begin{array}{l}\text { Resident history (past } \\
40 \text { years) }\end{array}$ & List where you lived, where you were born and how long you have lived (from the present to the past) \\
\hline \multirow[t]{13}{*}{ Occupational history } & Have you worked full time (more than 30 hours a week) for more than 6 months? \\
\hline & Have you worked in a dusty workplace? \\
\hline & Have you been exposed to gas or chemical vapors in your workplace? \\
\hline & What was your main job in your longest career? \\
\hline & What is your most recent job? \\
\hline & Are you currently engaged in agriculture? \\
\hline & How many years have you been engaged in agriculture? \\
\hline & Do you regularly incinerate crops every year? If you do, how often do you regularly incinerate crops? \\
\hline & Have you engaged in agriculture in the past? \\
\hline & If you have, how many years did you engage in agriculture? \\
\hline & Did you regularly incinerate crops every year in the past? \\
\hline & If you did, how often did you regularly incinerate crops? \\
\hline & Have you worked in a job using firewood? If you have, how often have you used firewood? \\
\hline \multirow[t]{8}{*}{ Household heating and fuel } & Did you use one of the following for heating in the past year: firewood stove (including fireplace), coal stove, electric \\
\hline & heater, or portable fuel/gas heater? \\
\hline & What kind of fuel do you use for household heating? \\
\hline & What kind of fuel do you commonly use for cooking? \\
\hline & If you use any kind of gas for cooking, how do you light it? \\
\hline & Have you used cooking stoves or ovens for household heating during the last winter? If "yes," how often did you use? \\
\hline & For cooking and/or heating, have you ever been exposed to fuels of wood or charcoal? \\
\hline & Among plant and animal waste fuel, which of the following was the most exposed for cooking and/or heating? \\
\hline
\end{tabular}

(Continued) 
Table SI (Continued)

\begin{tabular}{|c|c|}
\hline Category & Items \\
\hline & When was your first exposure to plant or animal waste fuel? \\
\hline & Are you being exposed to plant or animal waste fuel? (including a month ago) \\
\hline & How many hours are you being exposed to plant or animal waste fuel? \\
\hline & At what age did the exposure to plant or animal waste fuel disappear completely? \\
\hline & How many hours have you been exposed to plant or animal waste fuel a day? \\
\hline \multirow[t]{3}{*}{ Others } & What is your current marital status? \\
\hline & What is your educational background? \\
\hline & What is your household's monthly average income (total household income)? \\
\hline \multicolumn{2}{|l|}{ Surgical history } \\
\hline \multicolumn{2}{|l|}{ Family history } \\
\hline \multirow[t]{7}{*}{ Physical activity } & Do you regularly exercise enough to get sweat? \\
\hline & If you do, how many times do you exercise a week? \\
\hline & I usually exercise for about ___ minutes. \\
\hline & What kind of exercise are you doing? \\
\hline & How many hours did you do household chores a week in the past year? \\
\hline & How many stairs a day did you go up and down in daily life for the past year? \\
\hline & How many hours did you go for a walk in the past year? \\
\hline
\end{tabular}

Table S2 Demographics of moderate-to-severe COPD patients with or without bronchiectasis

\begin{tabular}{|c|c|c|c|c|}
\hline Values & All patients & $\begin{array}{l}\text { COPD without } \\
\text { bronchiectasis }\end{array}$ & $\begin{array}{l}\text { COPD with } \\
\text { bronchiectasis }\end{array}$ & $P$-value \\
\hline Subjects, n (\%) & $127(100.0)$ & $54(42.5)$ & $73(57.5)$ & \\
\hline Age* & $71.5 \pm 7.6$ & $69.8 \pm 8.1$ & $72.9 \pm 7.0$ & 0.024 \\
\hline Male & $107(84.3)$ & $47(87.0)$ & $60(82.2)$ & 0.459 \\
\hline Smoking status & & & & 0.830 \\
\hline Current & $43(34.7)$ & $18(34.0)$ & $25(35.2)$ & \\
\hline Former & $55(44.3)$ & $25(47.2)$ & $30(42.3)$ & \\
\hline Never & $26(21.0)$ & $10(18.9)$ & $16(22.5)$ & \\
\hline Pack-years smoked* & $30.3 \pm 25.2$ & $27.6 \pm 24.4$ & $32.6 \pm 26.0$ & 0.345 \\
\hline GOLD grade & & & & 0.387 \\
\hline Grade 2 & $107(84.2)$ & $45(83.3)$ & $62(84.9)$ & \\
\hline Grade 3 & $18(14.2)$ & $9(16.7)$ & $9(12.3)$ & \\
\hline Grade 4 & $2(1.6)$ & $0(0.0)$ & $2(2.7)$ & \\
\hline $\mathrm{BMI} *, \mathrm{~kg} / \mathrm{m}^{2}$ & $22.7 \pm 3.4$ & $23.1 \pm 3.1$ & $22.3 \pm 3.6$ & 0.194 \\
\hline Previous TB & $40(31.5)$ & $8(14.8)$ & $32(43.8)$ & 0.001 \\
\hline Pneumoconiosis & $8(6.3)$ & $5(9.3)$ & $3(4.1)$ & 0.490 \\
\hline MMRC $\S$ & $23 / 51 / 16 / 25 / 9$ & $10 / 23 / 6 / 9 / 5$ & $13 / 28 / 10 / 16 / 4$ & 0.939 \\
\hline CAT score* & $18.8 \pm 9.9$ & $18.7 \pm 10.7$ & $18.9 \pm 9.3$ & 0.904 \\
\hline \multicolumn{5}{|l|}{ Respiratory symptoms } \\
\hline Cough & $89(70.1)$ & $34(63.0)$ & $55(75.3)$ & 0.132 \\
\hline Sputum & $96(75.6)$ & $39(72.2)$ & $57(78.1)$ & 0.447 \\
\hline Dyspnea & $71(55.9)$ & $27(50.0)$ & $44(60.3)$ & 0.249 \\
\hline History of pneumonia & $12(9.8)$ & $6(11.5)$ & $6(8.6)$ & 0.717 \\
\hline History of asthma & $27(22.1)$ & $14(26.9)$ & $13(18.6)$ & 0.451 \\
\hline Exacerbations & $7(5.6)$ & $3(5.6)$ & $4(5.6)$ & 0.985 \\
\hline Steroid treatment & $3(2.4)$ & I (I.9) & $2(2.8)$ & 0.727 \\
\hline Hospital admissions & $5(4.0)$ & $2(3.7)$ & $3(4.2)$ & 0.883 \\
\hline Death, n (\%) & $4(3.2)$ & $3(5.6)$ & I (I.4) & 0.182 \\
\hline $\mathrm{WBC}^{*}, \times 10^{3} \mu \mathrm{L}$ & $6.8 \pm 1.9$ & $7.0 \pm 2.0$ & $6.7 \pm 1.8$ & 0.337 \\
\hline Segmenter neutrophils*, $\mu \mathrm{L}$ & $4,063.4 \pm I, 490.7$ & $4,120.0 \pm 1,630.1$ & $4,021.6 \pm 1,388.8$ & 0.715 \\
\hline Eosinophils*, $\mu \mathrm{L}$ & $186.3 \pm 215.3$ & $169.4 \pm 130.5$ & $198.9 \pm 261.1$ & 0.448 \\
\hline
\end{tabular}


Table S2 (Continued)

\begin{tabular}{|c|c|c|c|c|}
\hline Values & All patients & $\begin{array}{l}\text { COPD without } \\
\text { bronchiectasis }\end{array}$ & $\begin{array}{l}\text { COPD with } \\
\text { bronchiectasis }\end{array}$ & $P$-value \\
\hline Albumin*, g/dL & $4.1 \pm 0.3$ & $4.1 \pm 0.4$ & $4.1 \pm 0.3$ & 0.452 \\
\hline IL-6*, pg/mL & $2.6 \pm 3.1$ & $2.1 \pm 2.6$ & $3.0 \pm 3.4$ & 0.145 \\
\hline IL-8*, pg/mL & $16.5 \pm 17.1$ & $15.3 \pm 13.0$ & $17.4 \pm 19.9$ & 0.526 \\
\hline CRP*, mg/dL & $0.3 \pm 0.5$ & $0.2 \pm 0.3$ & $0.3 \pm 0.6$ & 0.119 \\
\hline $\mathrm{BDR}, \mathrm{FEV}_{1}, \mathrm{n}(\%)$ & 31 (24.4) & $19(35.2)$ & $12(16.4)$ & 0.015 \\
\hline BDR, FVC, n (\%) & $40(31.5)$ & $18(33.3)$ & $22(30.1)$ & 0.701 \\
\hline FVC*, \% & $86.3 \pm 14.8$ & $85.3 \pm 15.2$ & $87.0 \pm 14.5$ & 0.518 \\
\hline $\mathrm{FEV}_{1}^{*}, \%$ & $64.0 \pm 12.3$ & $64.7 \pm 11.8$ & $63.5 \pm 12.6$ & 0.573 \\
\hline $\mathrm{FEV}_{1} / \mathrm{FVC}^{*}$, ratio & $54.5 \pm 9.0$ & $56.0 \pm 7.6$ & $53.5 \pm 9.8$ & 0.122 \\
\hline Mean WA* & $70.2 \pm 5.4$ & $70.8 \pm 4.6$ & $69.7 \pm 5.8$ & 0.244 \\
\hline E/I-ratio ${ }_{M L D} *$ & $1.0 \pm 0.0$ & $0.9 \pm 0.0$ & $1.0 \pm 0.0$ & 0.016 \\
\hline El* & $9.7 \pm 8.5$ & $9.5 \pm 7.8$ & $9.9 \pm 9.1$ & 0.769 \\
\hline
\end{tabular}

Notes: Data shown are frequencies; those in parentheses are percentages. *Data shown are the mean \pm SD values, unless indicated otherwise. ${ }^{\S}$ Data shown as number of scores for each $\mathrm{mMRC}$ grade from $0-4$, respectively. Data in bold are statistically significant.

Abbreviations: BDR, bronchodilator reversibility; BMI, body mass index; CAT, COPD assessment test; CRP, C-reactive protein; El, emphysema index; E/I-ratio ${ }_{\text {LLD }}$ expiratory to inspiratory ratio of mean lung density; $\mathrm{FEV}_{1}$, forced expiratory volume in I second; FVC, forced vital capacity; GOLD, Global Initiative for Chronic Obstructive Lung Disease; IL, interleukin; MMRC, modified Medical Research Council; TB, tuberculosis; WA, wall area; WBC, white blood cell.

\section{Publish your work in this journal}

The International Journal of COPD is an international, peer-reviewed journal of therapeutics and pharmacology focusing on concise rapid reporting of clinical studies and reviews in COPD. Special focus is given to the pathophysiological processes underlying the disease, intervention programs, patient focused education, and self management protocols.

\section{Dovepress}

This journal is indexed on PubMed Central, MedLine and CAS. The manuscript management system is completely online and includes a very quick and fair peer-review system, which is all easy to use. Visit http://www.dovepress.com/testimonials.php to read real quotes from published authors. 